Check for updates

Cite this: RSC Adv., 2019, 9, 17975

Received 19th February 2019

Accepted 19th April 2019

DOI: 10.1039/c9ra01260e

rsc.li/rsc-advances

\section{Facile synthesis of 2-substituted benzo[b]furans and indoles by copper-catalyzed intramolecular cyclization of 2-alkynyl phenols and tosylanilines $\uparrow$}

\author{
Zhouting Rong, (D)* Kexin Gao, Lei Zhou, Jianyuan Lin* and Guoying Qian*
}

A catalytic amount of $\mathrm{CuCl}$ and $\mathrm{Cs}_{2} \mathrm{CO}_{3}$ was employed to synthesize a variety of 2-substituted benzo[b] furans and indoles by an intramolecular cyclization of 2-alkynyl phenols and tosylanilines. This protocol features mild conditions, high yields and broad substrate scope, which makes it a practical method for the synthesis of 2-substituted benzo[b]furans and indoles.

\section{Introduction}

The skeletons of benzo[b]furans and indoles are widely spread in many naturally occurring compounds $\mathbf{s}^{1,2}$ and pharmaceutical molecules. ${ }^{3,4}$ Many methods towards the synthesis of benzo[ $\left.b\right]$ furan and indole derivatives have been developed over the last two decades. ${ }^{5,6}$

To synthesize 2-substituted benzo[b]furans or indoles, the most universal method seems to be the Sonogashira coupling of 2-halophenols or 2-haloanilines with alkynes, followed by heterocyclization of the hydroxyl or amino group with the triple bond (Scheme 1, Pathway A). ${ }^{7}$ Some one-pot cascades have also been developed according to this strategy (Scheme 1, Pathway B) ${ }^{8}$ However, these transformations usually require the participation of noble metals, ligands or harsh conditions to complete the cyclizations.

Copper, in the merit of cost, is a superior choice in organic catalysis. ${ }^{9}$ It has also been used in the construction of benzo[ $\left.b\right]$ furan and indole rings. ${ }^{10}$ For example, Venkataraman and coworkers accomplished the synthesis of 2-arylbenzo[b]furans by exposing aryl acetylenes and 2-iodophenols to $10 \mathrm{~mol} \%$ $\left[\mathrm{Cu}\right.$ (phen) $\left.\left(\mathrm{PPh}_{3}\right)_{2}\right] \mathrm{NO}_{3}$ and 2 equivalents of $\mathrm{Cs}_{2} \mathrm{CO}_{3}$ in toluene at $100{ }^{\circ} \mathrm{C}$ for $24 \mathrm{~h}$. Similar transformations were realized with copper pincer complexes by Domínguez ${ }^{11}$ and with $\mathrm{Cu}(\mathrm{OTf})_{2^{-}}$ BINAM by Sekar. ${ }^{12}$ 2-Substituted indoles can also be obtained after the reaction of 2-ethynylaniline derivatives under reflux in $\mathrm{Cu}\left(\mathrm{OCOCF}_{3}\right)_{2}$ aqueous solution for $24 \mathrm{~h} \cdot{ }^{13}$ However, high reaction temperature and the use of stoichiometric amount of base are usually unavoidable to achieve high yields in these reactions. Herein, we report a facile and inexpensive method for the

College of Biological and Environmental Sciences, Zhejiang Wanli University, Ningbo 315100, People's Republic of China. E-mail: zrong@zwu.edu.cn; linjianyuan@zwu. edu.cn; qiangy@zwu.edu.cn

$\dagger$ Electronic supplementary information (ESI) available: General methods and experimental procedures, characterization and spectra of substrates and products. See DOI: 10.1039/c9ra01260e synthesis of 2-substituted benzo[b]furans and indoles by copper-catalyzed intramolecular cyclization of 2-alkynyl phenols and tosylanilines under mild conditions.

\section{Results and discussion}

Our studies started with the intramolecular cyclization of 2(phenylethynyl)phenol 1a as the substrate and the results were summarized in Table 1. When exposing 1a to different commercial available copper salts in dimethyl sulfoxide (DMSO), no reaction took place after $24 \mathrm{~h}$ at $23{ }^{\circ} \mathrm{C}$ (entries 1-5). Then 1 equivalent of triethylamine was added to each of these

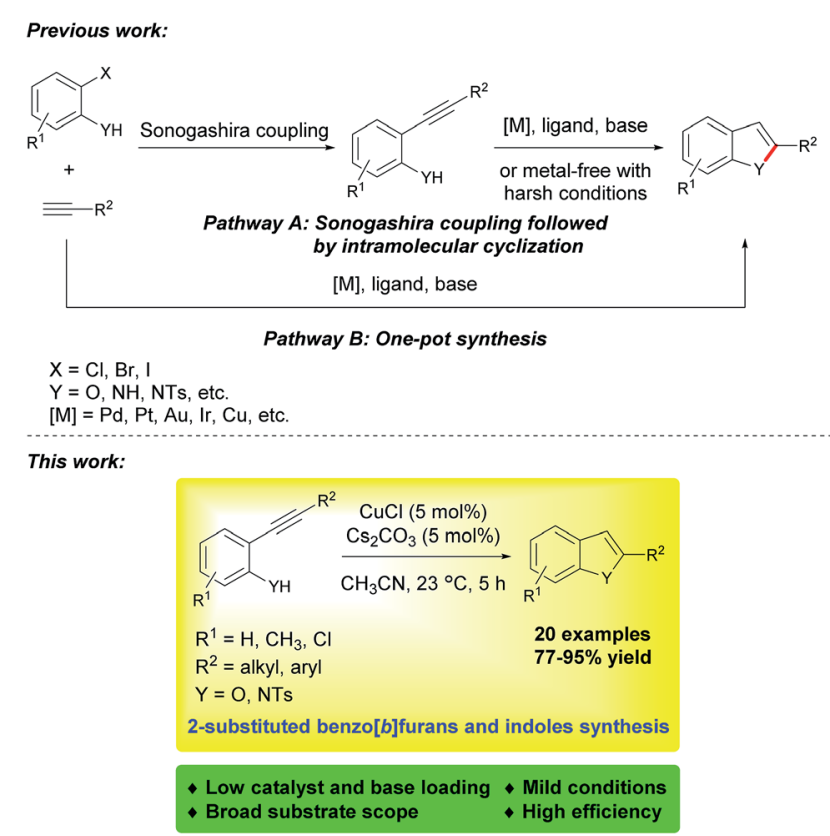

Scheme 1 Previous synthetic strategies for 2-substituted benzo[b] furans or indoles and our optimal conditions. 
Table 1 Optimization of reaction conditions ${ }^{a}$

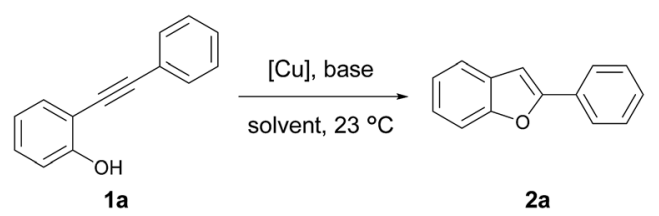

\begin{tabular}{|c|c|c|c|c|c|}
\hline Entry & {$[\mathrm{Cu}]$} & Base & Solvent & $\begin{array}{l}\text { Reaction } \\
\text { time (h) }\end{array}$ & $\begin{array}{l}\text { Yield }^{b} \\
(\%)\end{array}$ \\
\hline 1 & $\mathrm{CuCl}$ & - & DMSO & 24 & $\mathrm{NR}^{c}$ \\
\hline 2 & $\mathrm{CuBr}$ & - & DMSO & 24 & NR \\
\hline 3 & $\mathrm{CuCl}_{2}$ & - & DMSO & 24 & NR \\
\hline 4 & $\mathrm{CuBr}_{2}$ & - & DMSO & 24 & NR \\
\hline 5 & $\mathrm{Cu}(\mathrm{OTf})_{2}$ & - & DMSO & 24 & NR \\
\hline 6 & $\mathrm{CuCl}$ & $\mathrm{Et}_{3} \mathrm{~N}$ & DMSO & 48 & 48 \\
\hline 7 & $\mathrm{CuBr}$ & $\mathrm{Et}_{3} \mathrm{~N}$ & DMSO & 48 & Trace \\
\hline 8 & $\mathrm{CuCl}_{2}$ & $\mathrm{Et}_{3} \mathrm{~N}$ & DMSO & 48 & Trace \\
\hline 9 & $\mathrm{CuBr}_{2}$ & $\mathrm{Et}_{3} \mathrm{~N}$ & DMSO & 48 & 30 \\
\hline 10 & $\mathrm{Cu}(\mathrm{OTf})_{2}$ & $\mathrm{Et}_{3} \mathrm{~N}$ & DMSO & 48 & Trace \\
\hline 11 & $\mathrm{CuCl}$ & $\mathrm{Et}_{3} \mathrm{~N}$ & DMSO & 48 & 45 \\
\hline 12 & $\mathrm{CuCl}$ & DIPEA $^{d}$ & DMSO & 48 & 40 \\
\hline 13 & $\mathrm{CuCl}$ & Pyridine & DMSO & 48 & Trace \\
\hline 14 & $\mathrm{CuCl}$ & $\mathrm{DBU}^{e}$ & DMSO & 48 & 36 \\
\hline 15 & $\mathrm{CuCl}$ & $\mathrm{K}_{2} \mathrm{CO}_{3}$ & DMSO & 12 & 59 \\
\hline 16 & $\mathrm{CuCl}$ & $\mathrm{KOH}$ & DMSO & 12 & 55 \\
\hline 17 & $\mathrm{CuCl}$ & $\mathrm{Cs}_{2} \mathrm{CO}_{3}$ & DMSO & 12 & 84 \\
\hline 18 & $\mathrm{CuCl}$ & $\mathrm{Cs}_{2} \mathrm{CO}_{3}$ & $\mathrm{CH}_{2} \mathrm{Cl}_{2}$ & 12 & 61 \\
\hline 19 & $\mathrm{CuCl}$ & $\mathrm{Cs}_{2} \mathrm{CO}_{3}$ & $\mathrm{THF}$ & 12 & Trace \\
\hline 20 & $\mathrm{CuCl}$ & $\mathrm{Cs}_{2} \mathrm{CO}_{3}$ & Toluene & 9 & 69 \\
\hline 21 & $\mathrm{CuCl}$ & $\mathrm{Cs}_{2} \mathrm{CO}_{3}$ & DMF & 9 & 55 \\
\hline 22 & $\mathrm{CuCl}$ & $\mathrm{Cs}_{2} \mathrm{CO}_{3}$ & $\mathrm{CH}_{3} \mathrm{CN}$ & 3 & 95 \\
\hline $23^{f}$ & $\mathrm{CuCl}$ & $\mathrm{Cs}_{2} \mathrm{CO}_{3}$ & $\mathrm{CH}_{3} \mathrm{CN}$ & 5 & 95 \\
\hline $24^{f}$ & - & $\mathrm{Cs}_{2} \mathrm{CO}_{3}$ & $\mathrm{CH}_{3} \mathrm{CN}$ & 24 & NR \\
\hline
\end{tabular}

${ }^{a}$ Unless otherwise noted, all reactions were performed with $\mathbf{1 a}(0.2$ $\mathrm{mmol})$, [Cu] $(0.01 \mathrm{mmol})$, base $(0.2 \mathrm{mmol})$ at $23{ }^{\circ} \mathrm{C} .{ }^{b}$ The yield of $2 \mathrm{a}$ was determined by NMR with 1,3,5-trimethylbenzene as the internal standard. ${ }^{c} \mathrm{NR}=$ no reaction. ${ }^{d}$ DIPEA $=N, N$-diisopropylethylamine. ${ }^{e} \mathrm{DBU}=1,8$-diazabicyclo[5.4.0]undec-7-ene. ${ }^{f} 0.01 \mathrm{mmol}$ of $\mathrm{Cs}_{2} \mathrm{CO}_{3}$ was used.

reactions and we observed the slow formation of our desired product 2a, with $\mathrm{CuCl}$ giving the best yield (48\%) after $48 \mathrm{~h}$ (entry 6). This result pushed us to examine different commercial available bases using $\mathrm{CuCl}$ as the catalyst and DMSO as the solvent. After careful screening, $\mathrm{Cs}_{2} \mathrm{CO}_{3}$ stood out from a variety of organic and inorganic bases to give the best yield (84\%) after $12 \mathrm{~h}$ at $23^{\circ} \mathrm{C}$ (entry 17). We then tested various commonly used solvents and found out that acetonitrile dramatically accelerated the reaction to produce 2-phenylbenzo[b]furan 2 a with $95 \%$ yield after $3 \mathrm{~h}$ at $23{ }^{\circ} \mathrm{C}$ (entry 22 ).

To our surprise, adjusting the loading of $\mathrm{Cs}_{2} \mathrm{CO}_{3}$ to $5 \mathrm{~mol} \%$ did not cause any decrease in yield, although a slightly longer reaction time was needed (entry 23). When the experiment was carried out in the absence of $\mathrm{CuCl}$, no reaction took place after $24 \mathrm{~h}$ (entry 24), which suggested that copper catalyst was essential for this conformation although recently Gao and coworkers reported that this reaction could be completed at a higher temperature without any transition metal catalyst. ${ }^{14}$ Compared with other copper-catalyzed methods for benzo[ $b]$ furan synthesis, ${ }^{11-13,15}$ our optimized conditions featured lower catalyst and base loading, ambient temperature and ligand free.

With the optimal conditions in hand, we started to explore the substrate scope of this transformation and a variety of 2alkynyl phenols were employed. In general, this transformation showed good functional group tolerance and the results were listed in Table 2. 2-Arylethynyl phenols bearing either electrondonating or electron-withdrawing substitutes on the alkynylmoiety proved to be suitable substrates to produce the corresponding 2-aryl benzo[b]furans (2a-e) in good to excellent yields. To our delight, the presence of hydroxyl group did not interrupt the reaction, which afforded the desired benzo $[b]$ furans (2f-h) in excellent yields. 2-tert-Butylethynyl phenol and 2-phenylethynyl-3-hydroxyl pyridine also reacted smoothly to give the corresponding products in $91 \%$ and $88 \%$ yield, respectively.

Similar to 2-substituted benzo[b]furans, we proposed that 2substituted indoles could also be synthesized under our standard conditions. When 2-(phenylethynyl)aniline was used, however, no reaction was observed, probably due to the low acidity of the protons on the amino group. Hence, 2-(phenylethynyl)tosylaniline $\mathbf{3 a}$ was submitted to the standard conditions and the reaction proceeded smoothly to afford $\mathrm{N}$-tosyl-2phenyl indole $4 a$ in $95 \%$ yield. Then various 2-alkynyl tosylanilines were tested under the standard conditions and the results were shown in Table 3. We found that in all cases, 2arylethynyl tosylanilines gave the desired products $(\mathbf{4 a - c})$ in excellent yields. Similar results were obtained when different 2alkylethynyl tosylanilines (3d-f) were used as the substrates. Hydroxyl group was still tolerated in this transformation and tosylanilines with $\mathrm{Me}$ or $\mathrm{Cl}$ substitutes remained active to give the corresponding tosylindoles $\mathbf{4 i}$ and $\mathbf{4 j}$ in $86 \%$ and $82 \%$ yield, respectively.

Table 2 Substrate scope of benzo[b]furan synthesis ${ }^{a}$

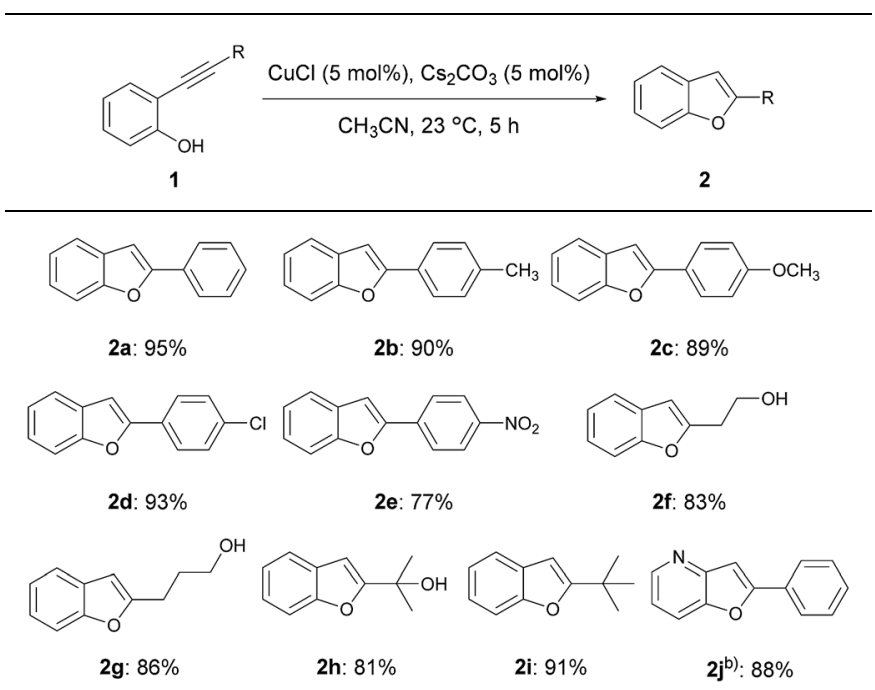

${ }^{a}$ All reactions were performed with $1(0.5 \mathrm{mmol}), \mathrm{CuCl}(0.025 \mathrm{mmol})$, $\mathrm{Cs}_{2} \mathrm{CO}_{3}(0.025 \mathrm{mmol})$ in $\mathrm{CH}_{3} \mathrm{CN}(2 \mathrm{~mL})$ at $23{ }^{\circ} \mathrm{C}$ for $5 \mathrm{~h}$. Isolated yields of 2 were listed. ${ }^{b}$ 2-Phenylethynyl-3-hydroxyl pyridine was used as the substrate. 
Table 3 Substrate scope of copper-catalyzed indole synthesis ${ }^{a}$

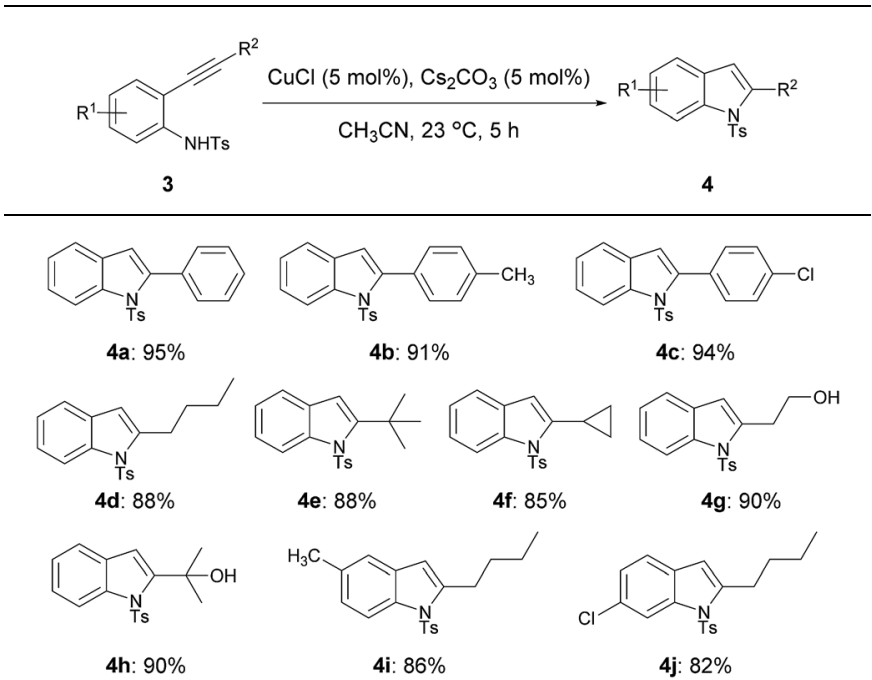

${ }^{a}$ All reactions were performed with $3(0.5 \mathrm{mmol}), \mathrm{CuCl}(0.025 \mathrm{mmol})$, $\mathrm{Cs}_{2} \mathrm{CO}_{3}(0.025 \mathrm{mmol})$ in $\mathrm{CH}_{3} \mathrm{CN}(2 \mathrm{~mL})$ at $23{ }^{\circ} \mathrm{C}$ for $5 \mathrm{~h}$. Isolated yields of 4 were listed.

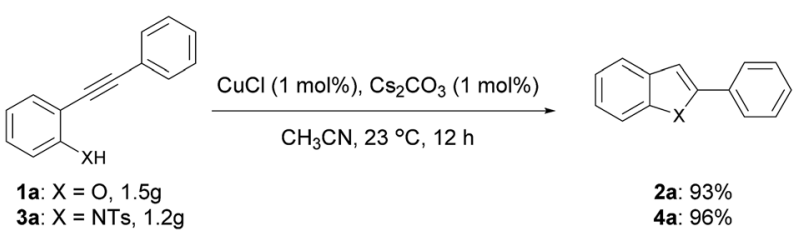

Scheme 2 Gram scale preparation of $2 \mathrm{a}$ and $4 \mathrm{a}$.

In order to demonstrate the utility and efficiency of this transformation, we performed the gram scale reactions of $\mathbf{1 a}$ and 3a in the presence of only $1 \mathrm{~mol} \%$ of $\mathrm{CuCl}$ and $\mathrm{Cs}_{2} \mathrm{CO}_{3}$ (Scheme 2). Although the completion time was longer, both reactions afforded the desired products in high yields. Considering the low cost and high yield, this robust method

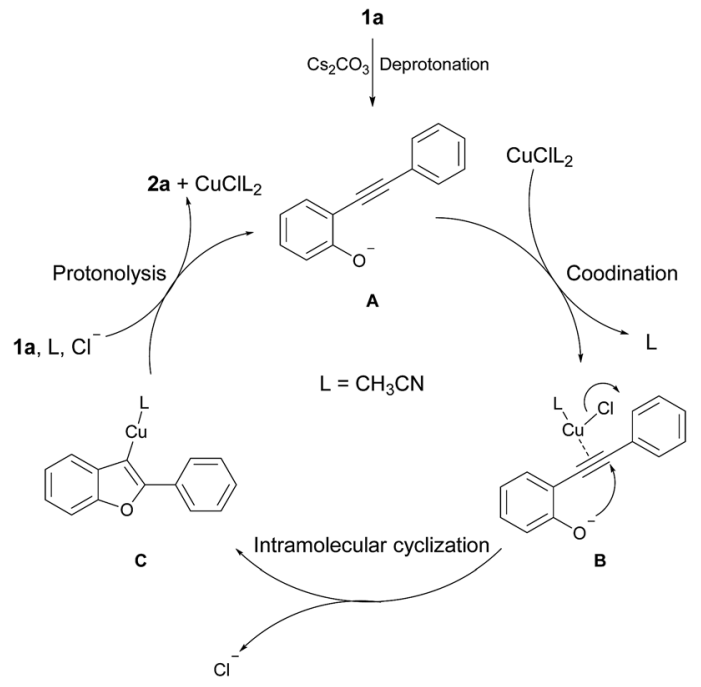

Scheme 3 Plausible reaction mechanism. offers a practical application for the facile synthesis of 2substituted benzo[b]furans and indoles.

A plausible mechanism of this reaction is then proposed taking 1a as an example (Scheme 3). At the outset, 1a can be deprotonated by $\mathrm{Cs}_{2} \mathrm{CO}_{3}$ to form $\mathbf{A}$, which can be activated by the solvated $\mathrm{CuCl}$ to afford intermediate $\mathbf{B}$. Then $\mathbf{B}$ undergoes an intramolecular cyclization to give intermediate $\mathbf{C}$. The subsequent protonolysis of $\mathbf{C}$ by $\mathbf{1 a}$ could afford our final product 2a accompanied with intermediate $\mathbf{A}$ for the next catalytic cycle.

\section{Conclusions}

In conclusion, a practical copper-catalyzed method has been developed for the facile synthesis of various 2-substituted benzo $[b]$ furans and indoles. The transformation can be accomplished under mild conditions with low catalyst and base loading, featuring broad substrate scope and high efficiency, which shows great potential in the application for the large scale production.

\section{Experimental}

General procedure for copper-catalyzed synthesis of 2substituted benzo $[b]$ furans and indoles

$\mathrm{CuCl}$ (2.5 mg, $0.025 \mathrm{mmol}$ ) and $\mathrm{Cs}_{2} \mathrm{CO}_{3}(8.1 \mathrm{mg}, 0.025 \mathrm{mmol})$ were added to a solution of 2-alkynyl phenol 1 (or 2-alkynyl tosylaniline $3,0.5 \mathrm{mmol})$ in $\mathrm{CH}_{3} \mathrm{CN}(2 \mathrm{~mL})$ and the mixture was stirred at $23{ }^{\circ} \mathrm{C}$ for $5 \mathrm{~h}$. Then $\mathrm{Et}_{2} \mathrm{O}(10 \mathrm{~mL})$ was added and the resulting mixture was washed sequentially with water $(10 \mathrm{~mL})$ and brine $(10 \mathrm{~mL})$, dried over anhydrous $\mathrm{Na}_{2} \mathrm{SO}_{4}$. The solvent was evaporated and the residue was purified by flash column chromatography (hexane/EtOAc) to give 2-substituted benzo[ $b]$ furans 2 (or 2-substituted indoles 4 ).

\section{Conflicts of interest}

There are no conflicts to declare.

\section{Acknowledgements}

This work was supported by the Zhejiang Provincial Top Key Discipline of Bioengineering (ZS2017014, ZS2018011 and ZS2015005), the Scientific Research Development Foundation of Zhejiang Wanli University and Zhejiang Provincial basic public welfare research project (LGN18H300001).

\section{Notes and references}

1 For selected examples of benzo[b]furan, see:(a) X.-D. Qin, Z.-J. Dong, J.-K. Liu, L.-M. Yang, R.-R. Wang, Y.-T. Zheng, Y. Lu, Y.-S. Wu and Q.-T. Zheng, Helv. Chim. Acta, 2006, 89, 127-133; (b) A. D. Patil, A. J. Freyer, L. Killmer, P. Offen, B. Carte, A. J. Jurewicz and R. K. Johnson, Tetrahedron, 1997, 53, 5047; (c) C.-K. Sha, S.-J. Huang and Z.-P. Zhan, J. Org. Chem., 2002, 67, 831. 
2 For selected examples of indole, see:(a) S. Hibino and T. Choshi, Nat. Prod. Rep., 2002, 19, 148; (b) T. Kawasaki and K. Higuchi, Nat. Prod. Rep., 2005, 22, 761; (c) M. Ishikura, T. Abe, T. Choshi and S. Hibino, Nat. Prod. Rep., 2013, 30, 694.

3 For selected examples of benzo[b]furan, see:(a) H. Khanam and Shamsuzzaman, Eur. J. Med. Chem., 2015, 97, 483; (b) A. Radadiya and A. Shah, Eur. J. Med. Chem., 2015, 97, 356; (c) J. Knoll, CNS Drug Rev., 2001, 7, 317.

4 For selected examples of indole, see:(a) F. R. de Sá Alves, E. J. Barreiro and C. A. M. Fraga, Mini-Rev. Med. Chem., 2009, 9, 782; (b) N. K. Kaushik, N. Kaushik, P. Attri, N. Kumar, C. H. Kim, A. K. Verma and E. H. Choi, Molecules, 2013, 18, 6620; (c) A. J. Kochanowska-Karamyan and M. T. Hamann, Chem. Rev., 2010, 110, 4489.

5 For selected papers on benzo[b]furan synthesis, see:(a) D. Yang, Y. Zhu, N. Yang, Q. Jiang and R. Liu, Adv. Synth. Catal., 2016, 358, 1731; (b) R. Ghosh, E. Stridfeldt and B. Olofsson, Chem.-Eur. J., 2014, 20, 8888; (c) C.-Y. Chen and P. G. Dormer, J. Org. Chem., 2005, 70, 6964; (d) L. De Luca, G. Giacomelli and G. Nieddu, J. Comb. Chem., 2008, 10, 517; (e) L. Ackermann and L. T. Kaspar, J. Org. Chem., 2007, 72, 6149; (f) X.-F. Duan, J. Zeng, Z.-B. Zhang and G.-F. Zi, J. Org. Chem., 2007, 72, 10283; (g) C. Eidamshaus and J. D. Burch, Org. Lett., 2008, 10, 4211.

6 For selected papers on indole synthesis, see:(a) G. R. Humphrey and J. T. Kuethe, Chem. Rev., 2006, 106, 2875; (b) S. Cacchi and G. Fabrizi, Chem. Rev., 2005, 105, 2873; (c) M. Platon, R. Amardeil, L. Djakovitch and J. C. Hierso, Chem. Soc. Rev., 2012, 41, 3929; (d) C.-Y. Zhao, K. Li, Y. Pang, J.-Q. Li, C. Liang, G.-F. Su and D.-L. Mo, Adv. Synth. Catal., 2018, 360, 1919; (e) Y.-Y. Liu, X.-Y. Yu, J.-R. Chen, M.-M. Qiao, X. Qi, D.-Q. Shi and W.-J. Xiao, Angew. Chem., Int. Ed., 2017, 56, 9527; (f) W.-Q. Liu, T. Lei, Z.-Q. Song, X.-L. Yang, C.-J. Wu, X. Jiang, B. Chen, C.-H. Tung and L.-Z. Wu, Org. Lett., 2017, 19, 3251; $(g)$ M. Shevlin, X. Guan and T. G. Driver, ACS Catal., 2017, 7, 5518; (h) Z.-Z. Zhang, B. Liu, J.-W. Xu, S.-Y. Yan and B.-F. Shi, Org. Lett., 2016, 18, 1776; (i) E. Marelli,
M. Corpet, Y. Minenkov, R. M. Neyyappadath, A. Bismuto, G. Buccolini, M. Curcio, L. Cavallo and S. P. Nolan, ACS Catal., 2016, 6, 2930.

7 (a) Y. Liang, S. Tang, X.-D. Zhang, L.-Q. Mao, Y.-X. Xie and J.-H. Li, Org. Lett., 2006, 8, 3017; (b) S.-X. Sun, J.-J. Wang, Z.-J. Xu, L.-Y. Cao, Z.-F. Shi and H.-L. Zhang, Tetrahedron, 2014, 70, 3798; (c) K. Damera, B. Ke, K. Wang, C. Dai, L. Wang and B. Wang, RSC Adv., 2012, 2, 9403; (d) L. Ilies, M. Isomura, S. Yamauchi, T. Nakamura and E. Nakamura, J. Am. Chem. Soc., 2017, 139, 23; (e) Y. Yin, W. Ma, Z. Chai and G. Zhao, J. Org. Chem., 2007, 72, 5731; (f) M. Nakamura, L. Ilies, S. Otsubo and E. Nakamura, Angew. Chem., Int. Ed., 2006, 45, 944; (g) M. Nakamura, L. Ilies, S. Otsubo and E. Nakamura, Org. Lett., 2006, 8, 2803.

8 (a) D. Sengupta, L. Radhakrishna and M. S. Balakrishna, ACS Omega, 2018, 3, 15018; (b) R. Zhou, W. Wang, Z.-J. Jiang, K. Wang, X.-L. Zheng, H.-Y. Fu, H. Chen and R.-X. Li, Chem. Commun., 2014, 50, 6023; (c) D. Saha, R. Dey and B. C. Ranu, Eur. J. Org. Chem., 2010, 6067; (d) M. J. Bosiak, ACS Catal., 2016, 6, 2429; (e) J.-R. Wang and K. Manabe, J. Org. Chem., 2010, 75, 5340.

9 For selected reviews, see:(a) X.-X. Guo, D.-W. Gu, Z. Wu and W. Zhang, Chem. Rev., 2015, 115, 1622; (b) S. E. Allen, R. R. Walvoord, R. Padilla-Salinas and M. C. Kozlowski, Chem. Rev., 2013, 113, 6234; (c) S. Reymond and J. Cossy, Chem. Rev., 2008, 108, 5359.

10 S. Cacchi, G. Fabrizi and A. Goggiamani, Org. Biomol. Chem., 2011, 9, 641.

11 M. J. Moure, R. SanMartin and E. Domínguez, Adv. Synth. Catal., 2014, 356, 2070.

12 E. A. Jaseer, D. J. C. Prasad and G. Sekar, Tetrahedron, 2010, 66, 2077.

13 K. Hiroya, S. Itoh and T. Sakamoto, J. Org. Chem., 2004, 69, 1126.

14 Y. Liu, W.-F. Tang and J. Gao, RSC Adv., 2018, 8, 28637.

15 (a) N. K. Swamy, A. Yazici and S. G. Pyne, J. Org. Chem., 2010, 75, 3412; (b) Z. Shen and X. Lu, Adv. Synth. Catal., 2009, 351, 3107; (c) R. Cano, M. Yus and D. J. Ramón, Tetrahedron, 2012, 68, 1393. 